\title{
مدى تأثير الفنون على المباني المعمارية
}

م.د. هبار هميدي مهيسن الرببعير

\section{ABSTRACT}

\section{Title :The extent of effect of Arts on Architectural Buildings}

Research paper contains of introduction followed by, importance, goals of research, samples and sources of information used. The research contained three chapters: The first chapter, presented the substance

of relation between Fine Arts and Architecture which included briefly, the main elements of design as: Idea, space, form, texture, color and style.

Second chapter is assigned to analyzing the main chosen four samples that related to the B.C., period, which are:

1- Statues at the gate of Abu Simble of Ramses in Egypt.

2- Colored and glazed gate of Babylon.

3- Statues of winged bulls at Dur Shiruken gate of Sargon in Ninewah.

4- Sculptured gate of Shitia from Ajanta caves in India.

The third chapter is an a comparative attempt to deal with eight specimens from later period that contained similar stance of relation between art and architecture. These specimens covered a vast period of later dates from the middle ages and modern, concentrated on Islamic Architecture and also works from the west.

Finally, , there are conclusions and references.

\section{مقدمة}

الفن هو العمل المبدع الذي يحقق السبق و الابتكار ـ و لا يقتصر مجال الفنون على ما هو شائع معرفته

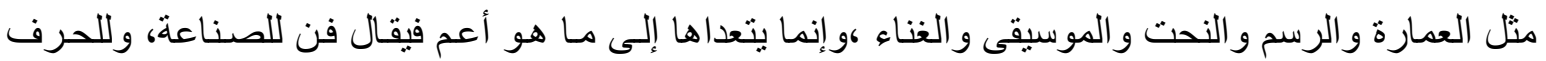
اليدوية وللفكر الذهني في العلوم التطبيقية و الإنسـانية كافة ـ ويختلف مفهوم (التشكيل) حسب المجال الفني رغم توحد أصوله العامة.و الفنون قد تكون مرئية، كالعمارة والنحت والرسم ويطلق عليها فنون السكون أيضـا. وقد تكون الفنون مسمو عة كالموسيقى و الغناء، وقد تكون مرئية مسمو عة كالبالية و السينما، وجميعها ترتبط بالإيقـاع و النغنم و التـوازن. وقد تكـون الفنـون تطبيقيـة للاسـتخدامات المختلفـة كالأثـاث و الأدوات و الأجهزة المختلفة والسيار ات والبو اخر وغير ها، وهو ما يعرف بالفنون الصناعية التي لا بد من توفر عنصر تحقيق الوظيفة فيها ، بجانب اختيار واختبار الثكل و اللون و الملمس ومـادة التصنيع*. والفنون ليست كمالية يمكن الاستغناء عنهـا أو تصنيفها في مرتبـة ثانويـة للمتطلبـات الحضـارية، إنمـا يجب أن تعطى لها الأولويـة في البر امج الدر اسية و الإعلامية وتصميم البيئة. وتولي المجتمعات فن العمارة أهميـة خاصـة على مر العصور، فهي تشكيل للفر اغـات و الأحجـام على ركيزة مـن الوظيفـة والعو امـل البيئيـة والاقتصـادية والثوابـت التراثيـة و والتقنية المتطورة.

ويعد اهتمـام الثـخص بـالفنون وكذللك قابليتهـه في ممارسـة الرسم و التصـوير أو النحت، مـن الأمـور

المساعدة لإمتهان العمارة ، حيث يساعده ذلك في رسم تصاميمه وتطوير ها و عرضـها وتعديلها بشكل أفضل. 
لذا فإن الدر اسات المعمارية تبدي اهتماما بتعليم طلابها مختلف الفنون وممارستها. كما إن بعض الجامعات تختبر استعداد الطـلاب المتقدمين لدر اسـة العمـارة فيها عـن طريـق التعـرف على اهتمامـاتهم وممارسـاتهر الفنية.و إن ما قدمه عباقرة عصر النهضة الإيطالية من الفنانين أمثنال ليونـاردو دافنشي كرسـام، ومايكل أنجلو كنحات ورسـام، في مجالات الرسم والنحت والتصميم المعمـاري، خير منثال. و على الرغم من أن اختلاف الحضـار ات و البيئـات الاجتماعيـة تعطي الفنـون و العمـارة خصوصـيتها ، إلا أن طبيعـة العلاقـة بـين الفنون و العمارة قدمت مشتركا عاما على مر العصور وفي كافة المناطق الجغر افية. ومن هنـا جاءت فكرة البحث عن تلك المثتركات في السجل الحضاري والتراث الثقافي للشعوب، لمعرفة أهميتها و قيمتها ومداها .

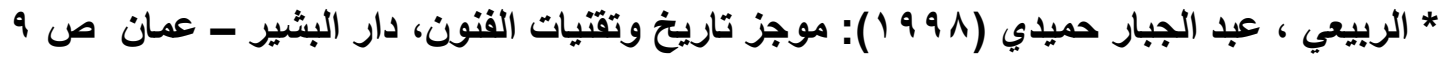
أهمية البحث: إن الفنون بمفهومها العام معروفة لدى الكثير من الدارسين، وكذلك العمارة. و الجديد في هذا البحث، يكمن في: ا - استعر اض للمباني التي ترتبط بالفنون. r- التعرف على بعض أنواع الفنون و علاقتها بأنو اع محددة من المباني المعمارية المستهدفة. rـ التعرف على مستوى العلاقة بين الفنون والمباني منذ أقدم العصور ومقارنتها بالعصور اللاحقة. عـ قلة الدراسات التي تناولت العلاقة بين الفن و المبنى. هـ التعرف على المستوى الثقافي للمجتمعات القديمة من خلال نتاجها الفني والمعماري. أهداف البحث: يهدف البحث إلى الوصول إلى:. 1 - تحديد مفهومي الفنون و العمارة ومدى العلاقة بينهما. r- الكثف عن الدلالات المشتركة بين الفنون و المباني المعمارية . rـ الكثف عن مدى التأثثر المتبادل و المشتركات بين الفنون و المباني المعمارية. الكثف عن الو اقع الاجتمـاعي للعصـور القديمـة مـن خـلال أدر الك مقدار العلاقـة بين أنواع الفنون والمبـاني المختلفة.

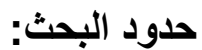

ا ـ الحد الزمني: عصور ما قبل الميلاد r- الحد الجغر افي : وادي الر افدين ووادي النيل و الهند r- الحد الموضوعي : الفن والعمارة عينة البحث: مباني مختارة 
مصادر جمع المعلومات:

المصادر و المر اجع المطبو عة عن الفنون و العمارة. المصادر والمر اجع الثانوية المطبو عة ذات الصلة بموضوع عن البحث. المواقع الالكترونية ذات العلاقة بموضوع البحث منهجية البحث : - من

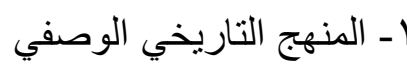
ب - المنهج التحليلي

\section{المبـحث الأول - ماهية العلاقة بيز الفنـون الجميلة والعمارة}

تعد العمـارة شكلاً مـن أشكال الفنون الجميلة وذات صـلة بها ـ تشترك معها في كثير مـن العناصـر المكونة لها كالخيال و الحس المبدع و إضفاء الجمال المبهج في التكوينات ،و إن أساس العمل فيها هو التصميم

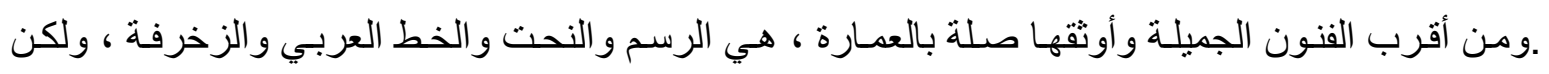

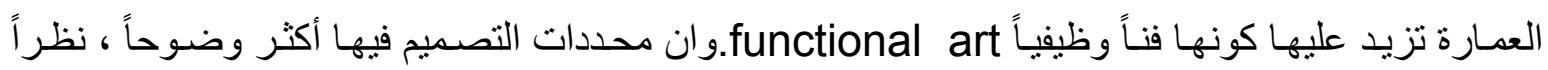
لارتباطها بأمور وجهات أخرى كصـاحب العمل والمبلغ المخصص والغايـة المستهدفة من المشـروع ـ بينمـا تكون حريـة الفنان في الأشياء و البنـاء التشكيلي مطلقة. ومن أهم المسـار ات التي تربط بين الفنون الجميلة

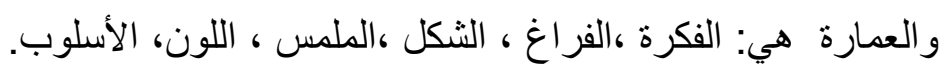

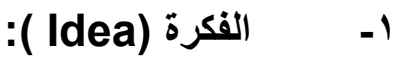

الفكرة ، هي الثرارة التي تحول عناصر التصميم إلى تكوين فني أو معماري،و الفكرة أمـا أن تكون قوية أو ضعيفة ، أو أن تكون أصيلة أو اعتيادية. والفكرة الأصيلة هي التي تؤدي إلى العمل الإبداعي، مثلمـا

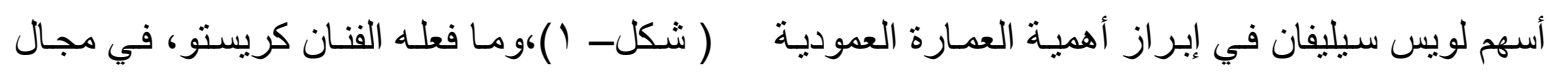

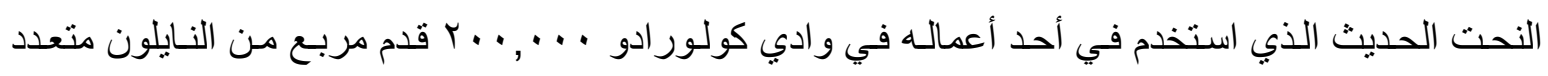

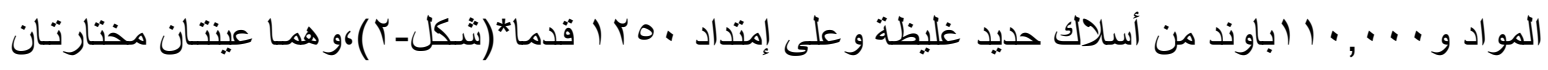
في الفن و العمارة، لتوضيح فكرة أصيلة وقوية التأثير.

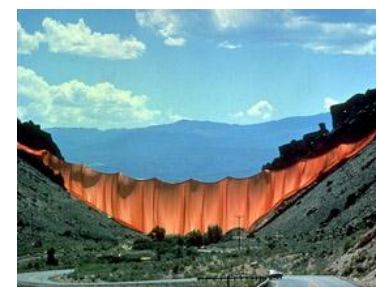

(شكل-2)الإبتكار في الفكرة والموضوع والمادة

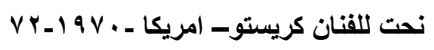

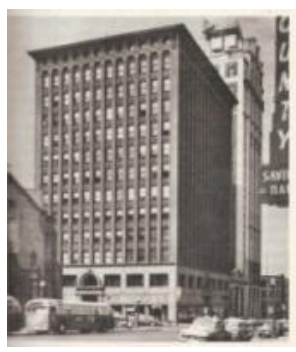

(شكل- ( ) السبق في فكرةالعمارة العمودية

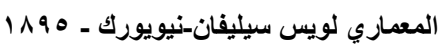

* Arnason H.H.,H.A (1982): History of Modern Art, .Abrams,N.Y.,p.648 


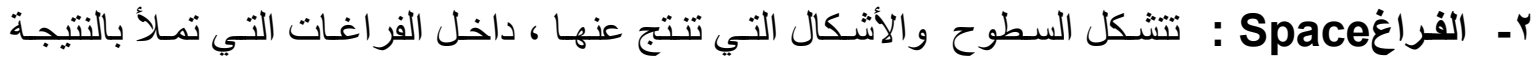
بالعناصـر الفنيـة المـر اد تحقيقها ضـمن تكوينـات مجتمعـة معينـة، كالتكوينـات الإنشـائية التشكيلية أو المبـاني السكنية الجماعية ، أو أن تأتي منفردة كلوحة أو تمثنال لشخص أو لدار سكن. مـع توفر القدرة على الإلمام

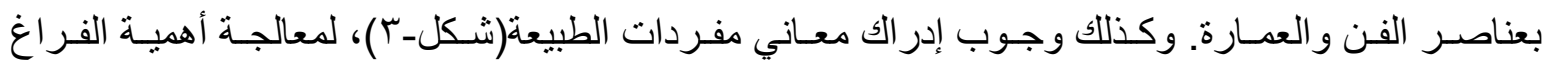
و الحركة المتوازنة المطلوبة داخله.

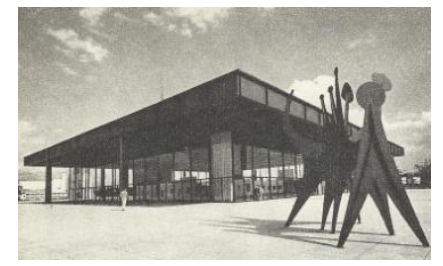

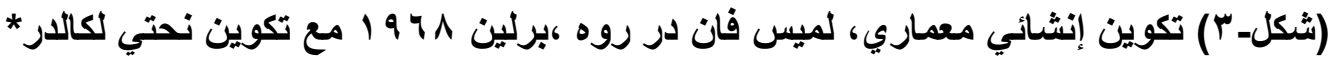
r-الثكل(SHAPE):عندما يرسم أو يصدم الثنكل في الفراغ، يتطور بنطور الفراغ الذي يحتويه**والثكل هو الذي يفسر مضمون العمل الفني وهو مظهره الخارجي،حيث لا يمكن أن ينفصل الثنكل عن المضمون في

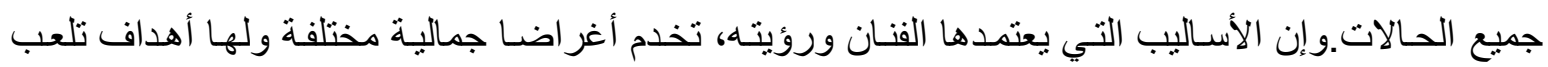
دورا في إيصـال الأفكـار إلى المتلقي،كمـا هـو الحسال في الهندسـة المعماريـة والإنشـاء التصـويري والنحت الجداري على سبيل المثال.كمـا يعّرف الثكل بأنه ، أي شيء لـه ارتفـاع وعرض كهيئة الإنسـان أو الطير

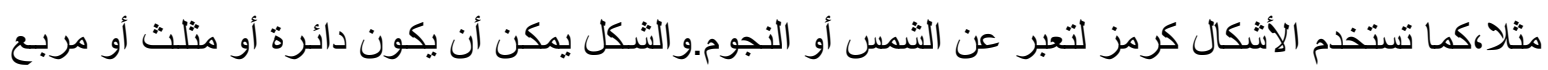
أو حرف أو شكل طبيعي أو سقف منحني أو منكسر. ويستخدم الثكل في التصميم المعمـاري لوصف مبنى معسين، وان المبنـى لـدى المعدـاري ، يعـرف و يتكـون مسن أثـكال هندسـية دائريـة وكرويـة واسـطو انية ومخروطية، تجمعت وفق أسس معينة على مستويات منتابعة مكونة الكتلة الخاصـة للمبنى (شكل-؟) .وللثكل أهمية كبرى في تكوينه التخطيطي و اللوني.فيمكن رؤيـة الثكل من خـلال إنشـاءه،مدلوله، علاقته بالطبيعة مـع الرؤية،ورمزيته على اختلافها.

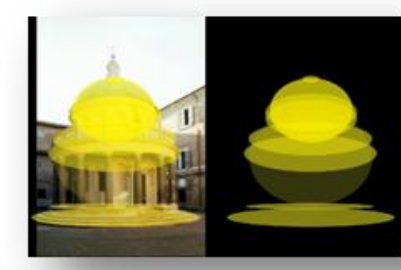

الثكل المعماري

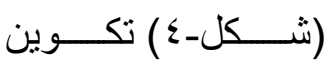

* Arnason, H.H. Abrams (1982): History of Modern Art ,N.Y., ,p 454

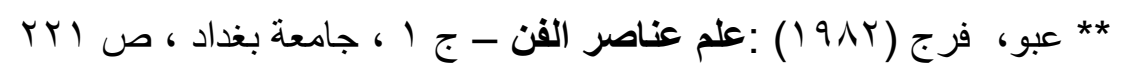


الملمس هو المظهر الخـارجي للأشياء والظـواهر المختلفة التـي تظهر أمامنـا من الأجسـام الطبيعيـة و الأجسام الهندسية والصناعية. ويمكن معرفة ملمس الأشياء القريبـة عند لمسهـا باليد ، أو تقدير ملمسهـا من خـلال رؤيتها عندما تكـون بعيدة نسبيا عنسا. وهنـاك المظهر الملمسي أو التركيب الملمسي (texture). وللخطوط أو الأشكال ملامس مختلفة، فمنها ناعمـة(smooth)ومنها خشنـة(rough)، ومنهـا مـا ملمسـه بين هذين الملمسين. ويمكن تلمس التباين و الانسجام باللمس اليدوي أو العين كمـا أسلفنا ـ و هناك مواد تحدد نوع الملمس الخـاص بها. فـالطين و الطـابوق و الحجر و الرخـام و الجبس و الخزف و الزجـاج و الخشـب و الحديـ و البرونز ، لكل منها ملمسه وجميعها تستعمل في البناء و النحت و الفخار . وكما للألوان المائية ملمسـها وكذلك الورق الذي ترسم عليه وللألوان الزيتيـة ملمسـها و القمـاش الذي ترسم عليه لـه ملمسـهـ وكمـا ان بعض هذه

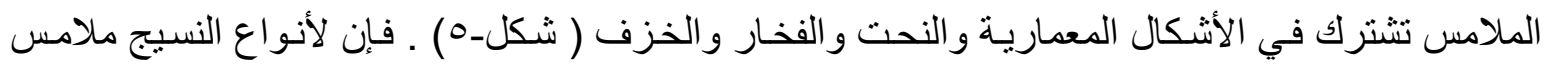

مختلفة كذنك (شكل-7).

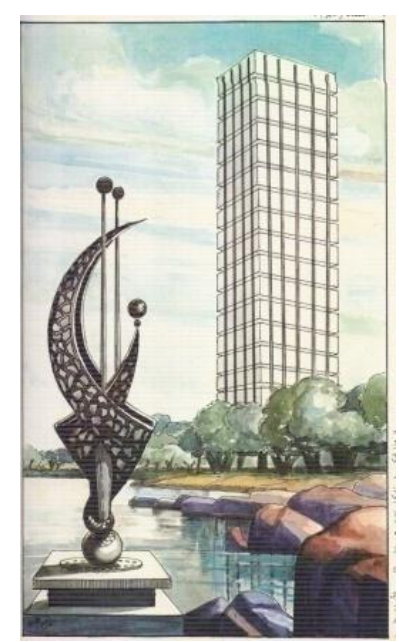

(شكل-0) أنواع الملمس المحسوس (تكوين تثكيلي)

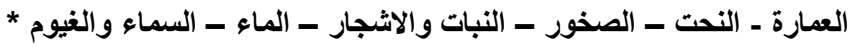

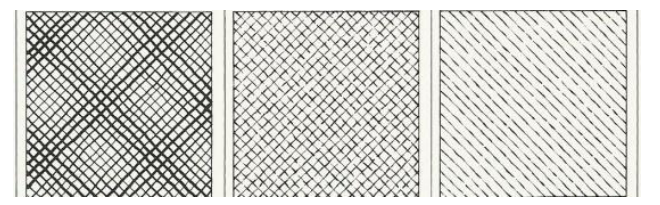

(ثكل-") أنواع من الملمس الخطي لمختلف السطوح والنسيج ب بالتشكيلات المختلفة للخطوط

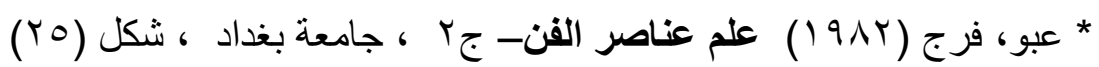

•- اللون (COLOUR):

الألو ان ظاهرة جذابة تلعب دور ا عاطفيا في تقبلنا للأشكال. وتحدد الألوان بقو انين وظو اهر ، وكل لون له قيمةهوتكون هذه القيمة محددة بخط أو موزعة للتجاور مع لون أو مجموعة من الألوان الأخرى.ومصسادر اللون هي الضوء والطبيعة وواسطة الرؤيا هي العين، و إن أهم مصدر للضوء في الطبيعة هو الثمس.ويعطي اللون قيما متفاوتة في صياغة الهيئة التي تتكون من الأشكال و المنظور، و يعطي متعـة وموازنـة جمالية بين ألو ان اللوحة و المبنى على حد سو اء.و الألوان لها معنى ودلالة ورمزيـة كالعلامـات المروريـة وأعلام الدول 
و غير ها.كما تستخدم الألو ان في العمارة بكثرة وفي تعريف الفضاءات الداخلية و الواجهات الخارجيـة للمباني ،

وفي التصـميم الداخلي و الإضـاءة المسرحية والنحت بالضـو ، ، وإضـاءة العهـار ات والصـالات في الهندسـة

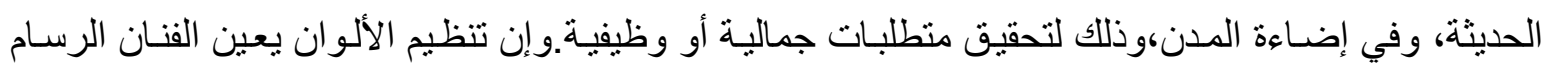
و المعماري على حد سواء،في كيفية الاستفادة من العلاقات و المضـادات اللونية وفصـائلها الحارة worm ) (cold colors)و في إنجاز الفنان لعمله التشكيلي، والمعماري من خلال تعامله مـع واجهة المبنى و جدر انه الداخلية (شكل-V) (

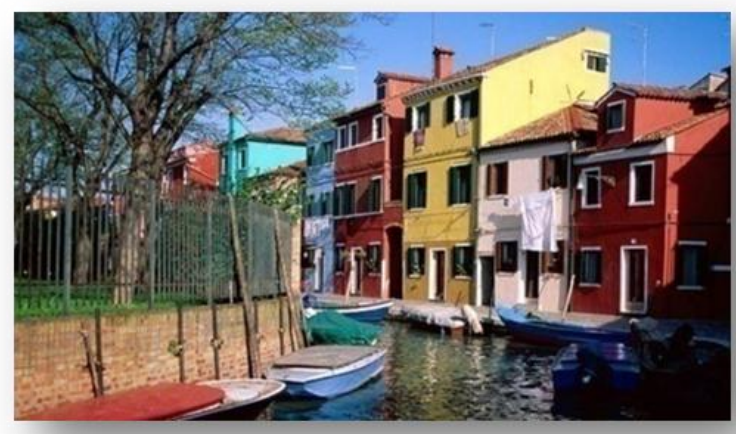

(شكل-V) استخدام اللون في المباني المعمارية والزوارق

ك- الأســلوب في الفن والعمارة STYLE

عندما يتميز الفنان أو الأديب أو الموسيقار في أعماله بصفات نـادرة وبـارزة ، فانه بـللك يكونّ أسلوبه الخاص به.و هكذا الحال في العمارة في حالة كونها ذات خصائص مميزة من الأشكال و الصيغ العامـة الثـائعة ، و إن الأسـلوب المعدـاري يظهر غالبـا وبصورة واضحة في الواجهات الخارجيـة للمبنى .ويمكن تصنيف الأساليب كما يلي:

FORMALISM الأسلوب الشكلي 1-6 وفيه يجري الاهتمام بالثكل والهيئة فتعطى له الأولوية في التكوين،حيث تكون الكتل صـانعة للحيز ،كما في أعمال الفنان مايكل أنجلو المعمارية (شكل-^)،و عمل المعمـاري الفرنسي لي كوربوزيـه في كنيسـة نوتردام في رونشام (شكل-9 )، وتصميم مبنى متحف كوكنهام في نيويورك للمعماري الأمريكي فر انك لويد رايت.كما يمكن ملاحظة النزعة للنكل في أعمال النحات كريستو (راجع شكل-Y).

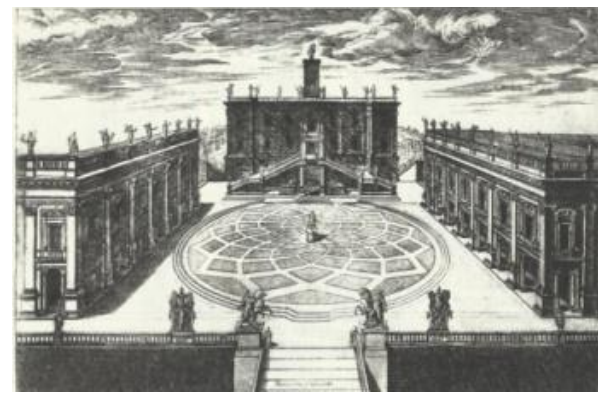

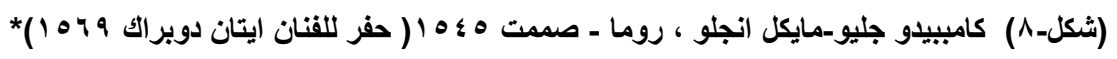




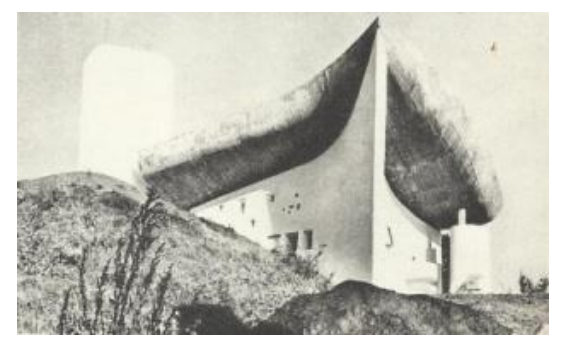

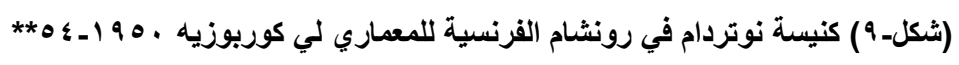

* Janson H.W (1980).: History of Art Abrams , N.Y. , p. 430

${ }^{* *}$ H.H. Arnason : () ,Abrams History of Modern Art: , N.Y. , p 452

FUNCTIONALISM 2-7 الأسلوب الوظيفي

وفيه يكون الاهتمام الأول بالوظيفة وإن كانت محددة للشكل، ويمكن الإستدلال على مثل هذا الأسلوب

ففي الأبنية الصناعية ذات الأغر اض المختلفة والملاعب الرياضية والمطار ات وما شابهها (شكل-10).

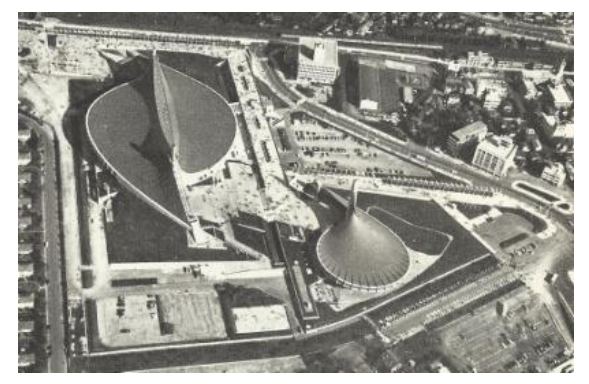

* (شكل-10) مباني الألعاب الرياضية الوطني- منظر جوي - للمعماري كينزوتانجي، اليابان ع 9 أ

\section{ROMANTICISM T- الأسلوب الرومانتيكي}

الأسلوب الرومانتيكي هو الأسلوب الذي عبر فيه الفنانون عن ميولهم في الخروج عن المـألوف في

الفكرة وطريقة تنفيذها والتعبير عن المواضيع بنوع من المبالغة واستخدام الخيال ** ويجري فيه التركيز

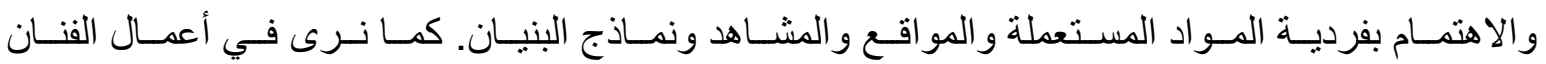
ديلاكروا،وكذلك الفنان هنري مور ، وأعمال المعماري (كاودي) الذي أصبح أسلوبه ، ماركة مسجلة*** في التصميم المعماري، أمثلة على ذلك (شكل-11).

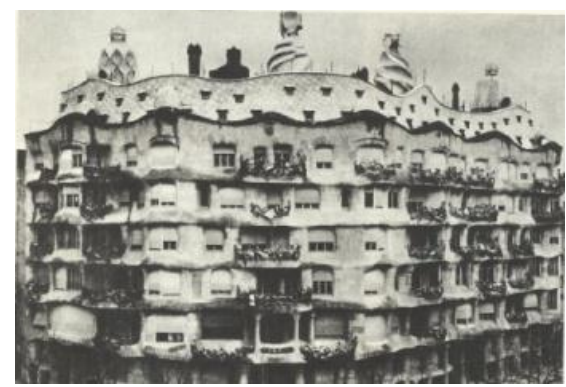

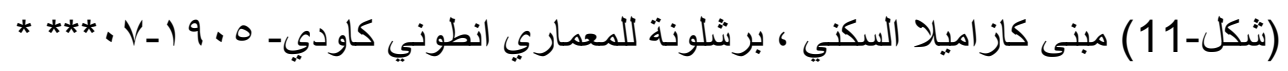

*Arnason, H.H.,Abrams (1982): History of Modern Art, N.Y., p 477 
** الربيعي، عبد الجبار حميدي ( مرجع سابق)، ص 9 ^؛ ***, Arnason, H.H (1982). History of Modern Art , N.Y, , p.86

**** Arnason, H.H (1982):: p 704

דECHANICALISM الأسلوب الآلي

ويجري فيهه إتباع أسلوب وقو انين في التصميم على أسـاس أن كل شيه،يجب أن بعمل بدقـة ونظسام كالآلة.وتعطى فيه للتخطيط الوظيفي قيمته فيكثف عن هيكل البناء لبيان وظيفته،ويقلل من شـأن الاختلافات الفردية لصالح الأشكال .و إن ما يؤكد أيضاً على الأسلوب الآلي في التصميم المعداري هو قول هول المعماري-

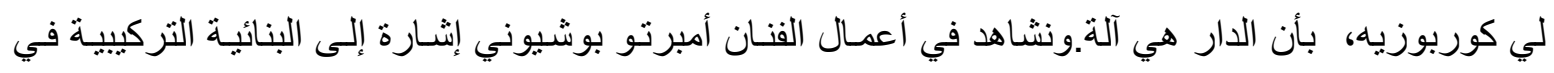
الفن و التي توحي بحركة آلية للشكل، (شكل-12).

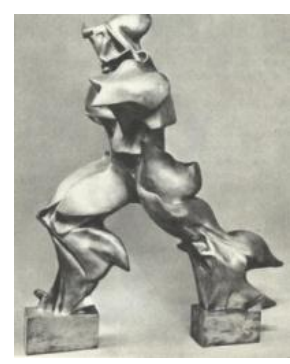

* (شكل-12) استمرارية في الفراغ ، نحت برونز ، الفنان امبرتو بوشيوني با (9

דRGANISM - 5 الأسلوب العضوي

ويميل فيه الاتجاه التصميمي إلى التركيب العضوي للأحياء كالنباتـات أو الحيوانـات.وهو يقترب من

الأسلوبين الرومانتيكي والآلي من حيث، ملائمة الأشياء الحية لمحيطها ومن حيث تحديد القوانين الطبيعيـة الطئ شكل-13).

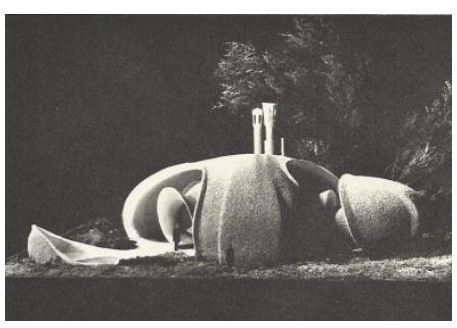

** 190 مشكل-13) مشروع بيت على شكل زهرة للمعماري جون جو هانسن

* Janson, H.W.:( 1980), p 683

** Arnason, H.H.:( 1982) , p.498

\section{المبـهث الثناني - العينات}

عند التصدي لموضوع العلاقة بين الفنون التشكيلية وفن العمارة ، لابد من الاعتر اف بأن الرسم و اللون، كانا قد مارسهما إنسان الكهوف في مختلف مناطق العالم قبل أن يبني مسكنا يستقر فيه ، و الذي جاء 
في فترة لاحقة. و عن مدى علاقة تلك الفنون بالمباني، يمكن أن نستعرض أبرز الثواهد المعماريـة المختارة ، التي تبرز فيها تلك العلاقة بوضوح. و وهذه الثوا هد المختارة هي: بكئ - - بوابة معبد أبو سمبل في مصر - - بوابة قلعة سرجون الثاني في نينوى - بوابة شيتيا- كريها ، كهوف أجانتا في الهند وجميعها تتبع لحقبة ما قبل الميلاد .

لأجل المقارنة والمقاربة لما حدث بعد ذلك، فمن المفيد التعرض لبعض الثوا اهد من العصور الزمنيـة اللاحقة. وخير مثال على تللك الثوا هد ، ما قدمته الحضارة الإسلامية في الثرق و الأوربية في الغرب. بوابة معبد أبو سمبل في مصر:

واجهة بوابة معبد أبو سمبل الموجود في الأقصر، و والذي بنـاه الملك الفرعوني رمسبس الثناني من

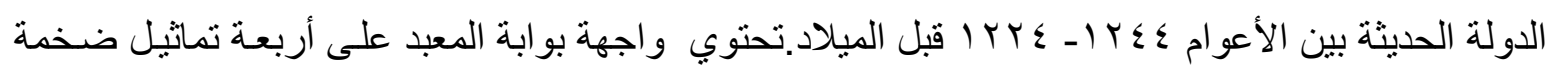
بوضع الجلوس تمثل رمسيس الثاني ، تتوزع اثنان على كل جهة من المدخل الرئيسي للمعبد( شكل-14- ( ) ـ نحتت التماثيل في الصخر بحجم الواجهة وتمثل نصبا تذكاريا لرمسبس. يرتفع كل واحد منها أكثر من أربعين قدما * أي أن التماثيل لأربعة المنحوتة على الحجر بضخامتها وارتفاعها، تهيمن على واجهة المبنى، لئل كما ان وضعية الجلوس الحادة التي يظهرون بها ، تعبير عند الفراعنة كما يبدو، على قوتهم وسبطرتهم . ويقع بقرب هذا المعبد، معبدا آخر خصص لزوجته نفرتاري ( شكل-14-Y) .

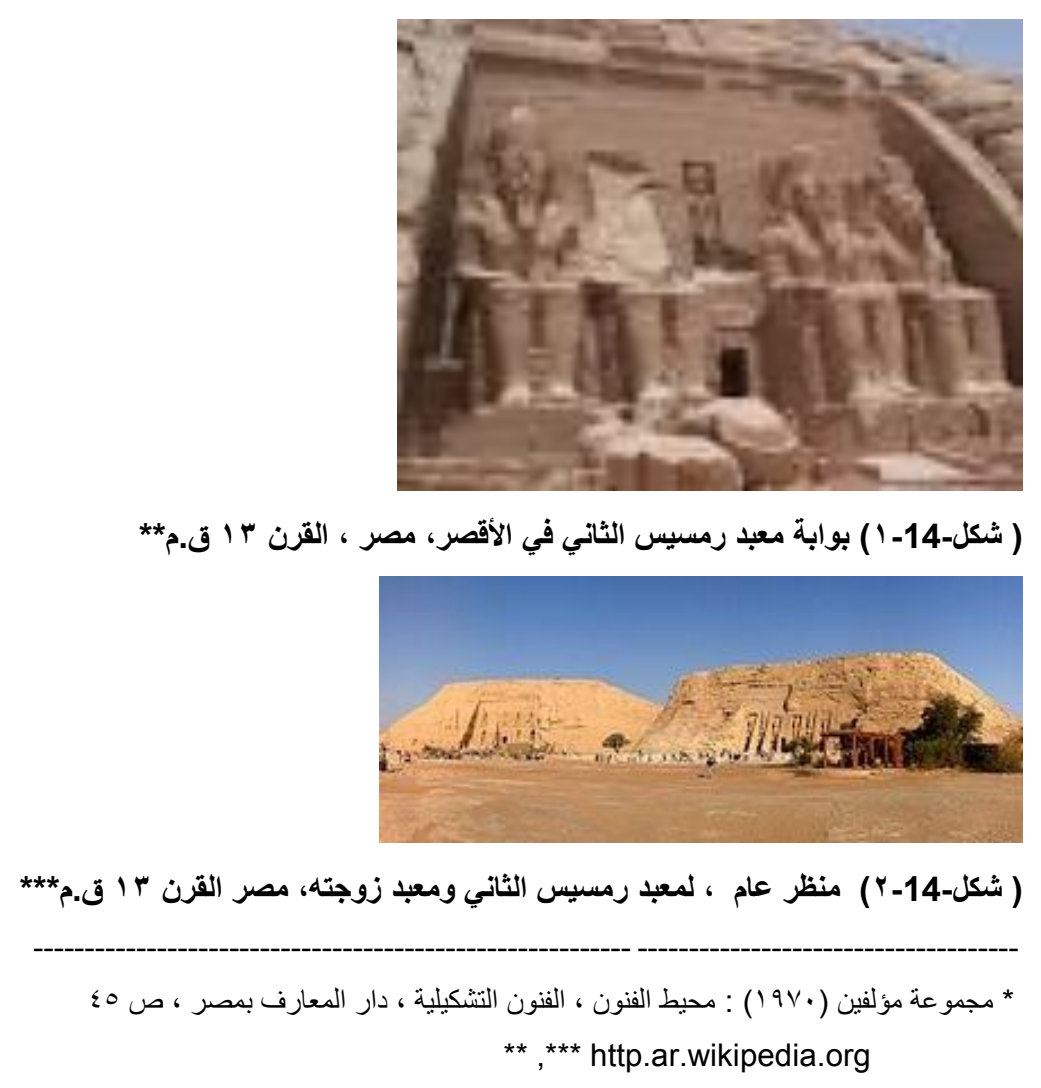




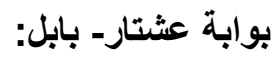

بوابة عشتار البابلية ، المدخل الرئيسي للمدينـة البابلية هي البوابـة العجيبـة بحجمها وتصميمها وتقنيات بنائها وتتفيذ منحوتاتها التي احتوت على ثير ان وتتانين وحيو انات أخرى و على زخارف متتو عـة ، وجميعها مزججة بأجمل

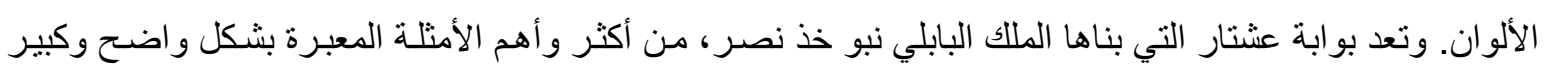

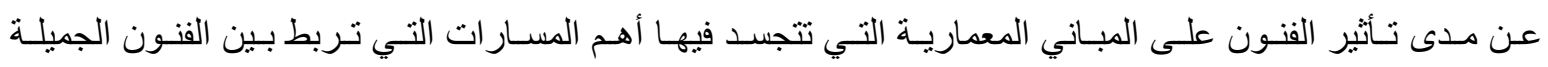
و العمارة،وهي الفكرة و الفر اغ و الثكل و الملمس و اللون و الأسلوب. و هي من حيث الفكرة و الفراغ ، فريدة ومميزة،

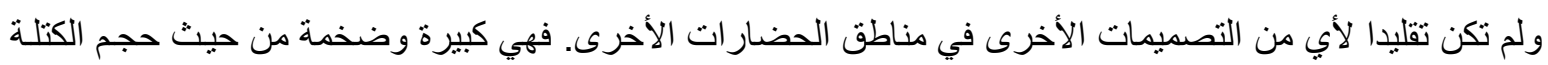

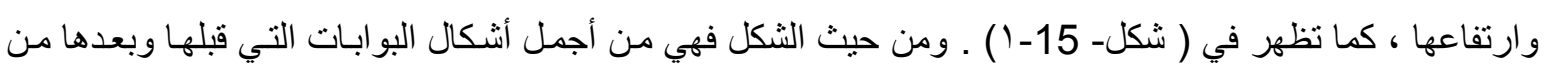

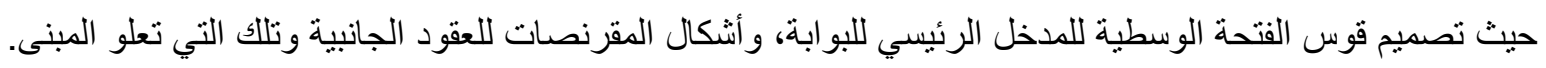
و هي من حيث ملمسها ، فهو يجمع بشكل واضح وجلي، بين النحت البارز و الفخار المنفذ بالآجر أو القرميد المزجج. أما من حيث ألو انها الفريدة التي تعكس مدى الرقي في المعرفـة العلميـة في التعامل مـع تحضير الألوان

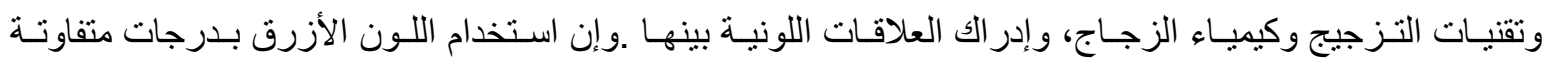
ومنسمة للخلفيات، واستخدام الأزرق الفيروزي المخضر لتيجان أعدة المشربيات واللون الأصفر الذهبي المحروق

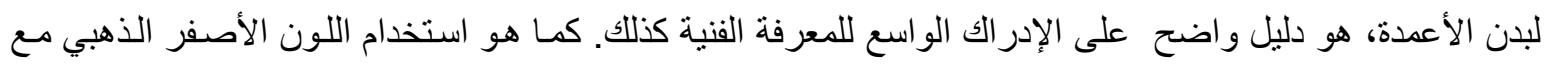
النحت الجداري ، مع اللون الأصفر الداكن أو ما يشبه البني المحروق في الأشرطة الزخرفية التي تسير عليها لإنها الثيران

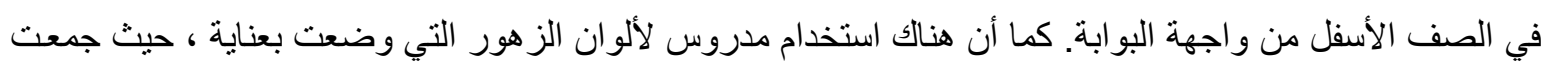

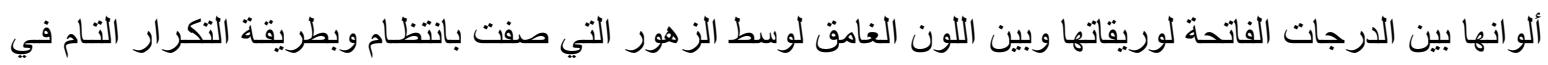

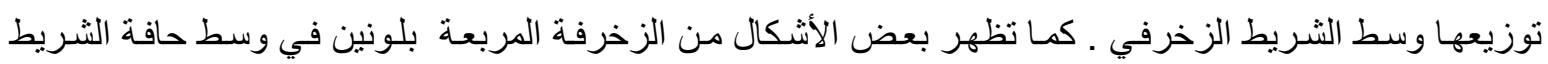

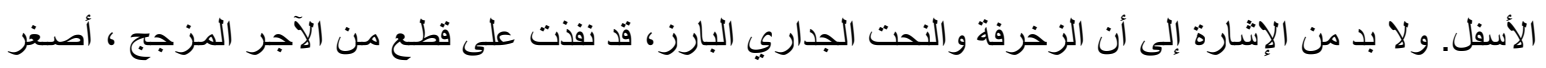

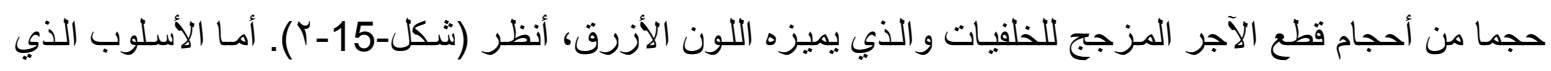

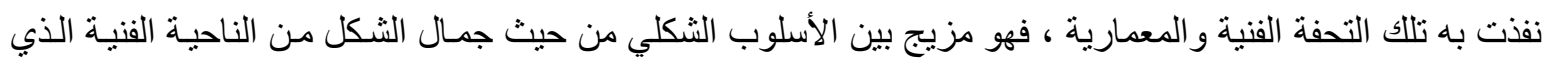

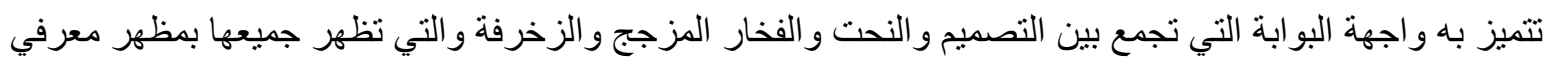

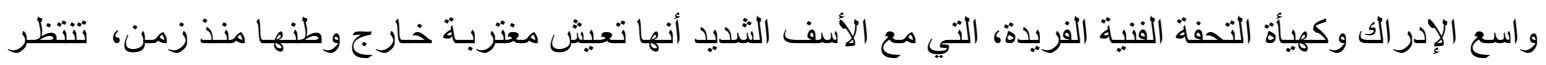
عودنها يوما إلى أبناءها ووطنها.

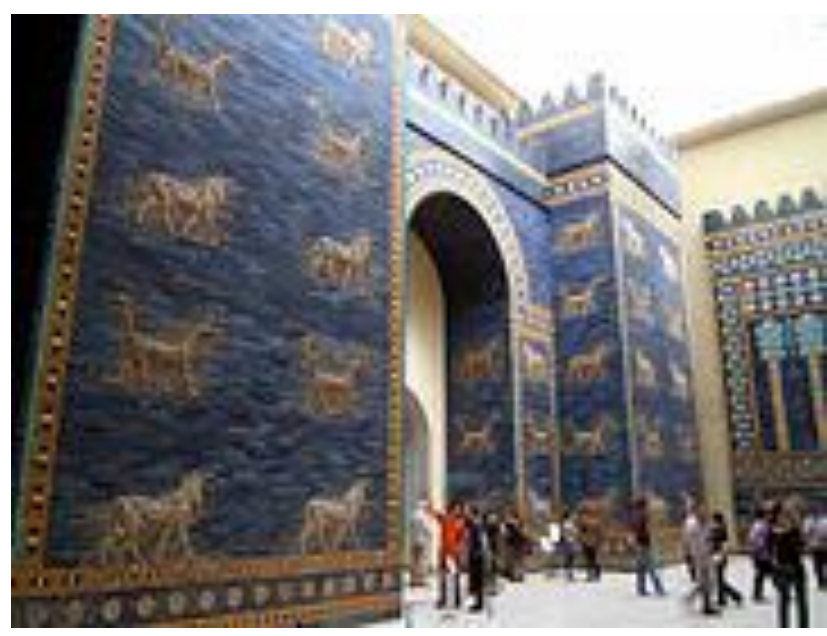

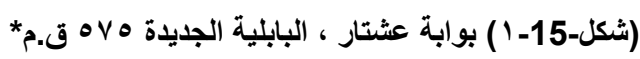




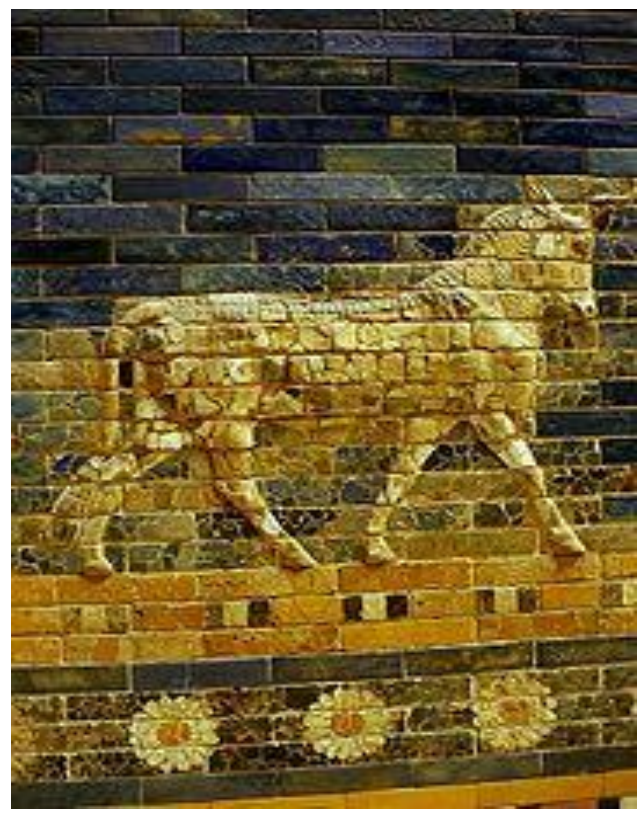

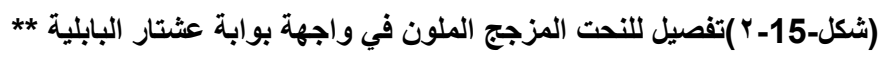

${ }^{*},{ }^{* *}$ http.ar.wikipedia.org

\section{بوابة دور شيروكين- آشور:}

فكرة الثير ان المجنحة ظهرت في نمـرود ، وهـي التسمية التي أطلقت لاحقا على بقايـا عاصمة الآشوريين (كالخو) التي بناها الملك الآشوري (شلمنصر الأول)، وبعد ذلك أعاد الملك (ناصربال الثاني) بنـاء تلكك المدينة خلال حكمه في النصف الأول من القرن التاسـع قبل الميلاد ، وزود بو ابتها بتماثيل ضخمة من الت الثثران المجنحة والتي كانت ترمز للمعتقدات الآشورية في ذلك الوقت.

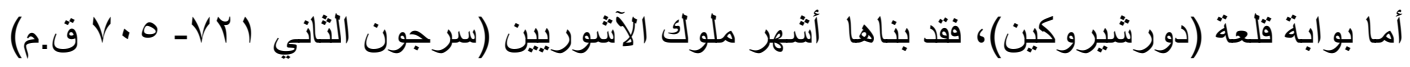
و الذي حكم وأو لاده وأحفاده حتى سقوط العاصمة نينوى عام r الح قبل الميلاد. ومن المؤكد ان الآشوريين كما هم البابليون قد عرفوا تقنيات الآجر المزجج ولكنهما تعملوا هذه التقنية داخل المباني ـ واستخدموا عند

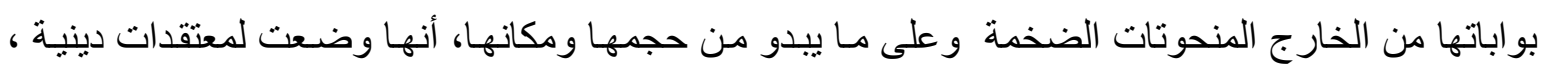
وللالالتة على هيبـة الدولـة والقوة ، ولغرض الحراسـة لإخافـة الأعداء (شكل-16- (). و وتذكر المصـادر ان الملك سرجون الثاني قد (استعمل القانــني المزجج الأزرق ، و المزخرف بالصور والرموز في العاصمة الجديدة (دور شيروكين) التي اكتشف فيها جـ ثور ا مجنحا ، يزن كل واحد منها حو الي أربعين طنا))*. ومن ودن خلال مقارنة حجم الثثران المجنحة بالنسبة إلى حجم البوابة ، يتسنى لنا تقدير ضخامة حجم تللك الثيران التي

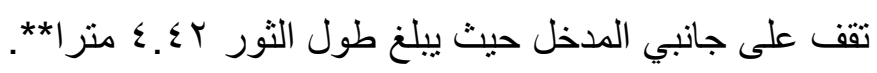

و الثور المجنح من حيث الفكرة ،يعبر بشكل واضـح عن استيعاب الفنان الآشوري لمضمون الفكرة و إبداعه وقدرته الفائقة في التعبير عنها. وان استخدام ذلك الفنان لفكرة الجسد لهذا الحيوان الذي يمثل مصدر من مصادر القوة، والإستعاضة عن رأسه برأس ووجهه إنسـان وباللباس وتسريح الثـعر الآشوري التقليدي ، 
و الإيحاء بفكرة المطاردة بالإنتقال السريع عند الضرورة ، بواسطة الطيران من خلال وضع جناحين كبيرين لله،كما ان وجود خمسـة أرجل لهذا الجسم الأسطوري والتـي تجمع بوجودهـا بين حالتي الوقوف و الحركة بنفس الوقت ، فـإن كل تلك الرمزيـة في الفكرة، وربطها بو اقعيـة الأسـلوب، إنمـا تـدل على ذكاء الفنـان الآشوري الخارق،ودليل و اضح عن نضـج أفكار ه،ومدى الأفق الثقافي الواسـع لديـه (شكل-16-Y). ويمكن القول أن وجود تللك التماثيل وبهذا الحجم الكبير وبهذه الرمزيـة المركبة، عند مدخل البوابـة ، لا يمكن إلا أن تكون جز ءا مهما من تصميم البناء المعماري لهذه البوابة وما يستقر وراءها من مباني ، بحيث لا يمكن أن

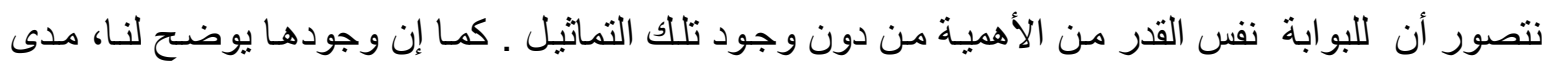
التأثير الإيجابي الذي تتركه تللك الأعمال الفنية على البناء المعماري.

* رشيد ، فوزي (919 1) : آثور أفق السماء ، بغداد ، ص 0 ؛

** http.ar. Wikipedia.org

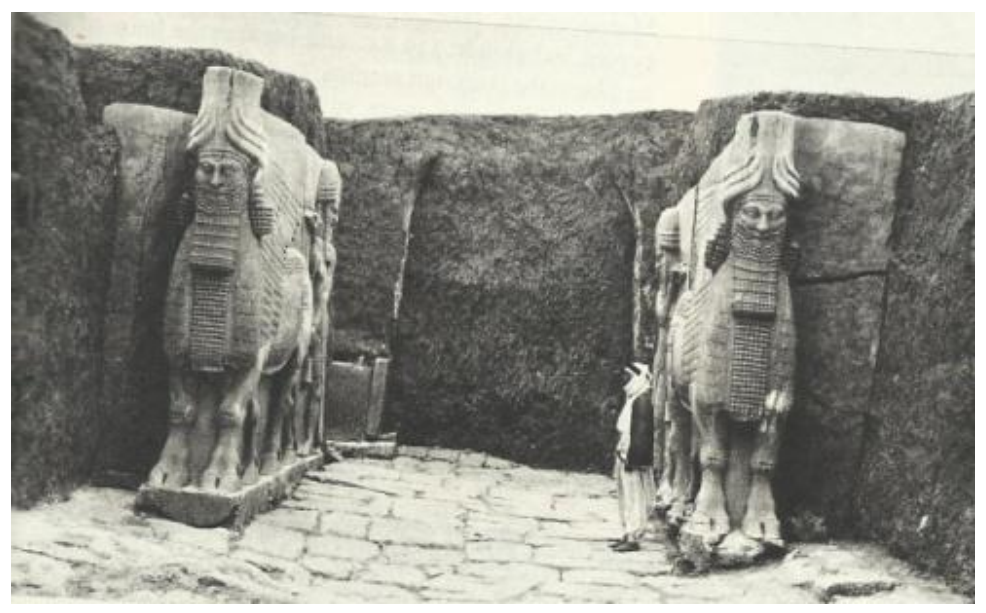

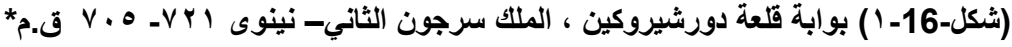

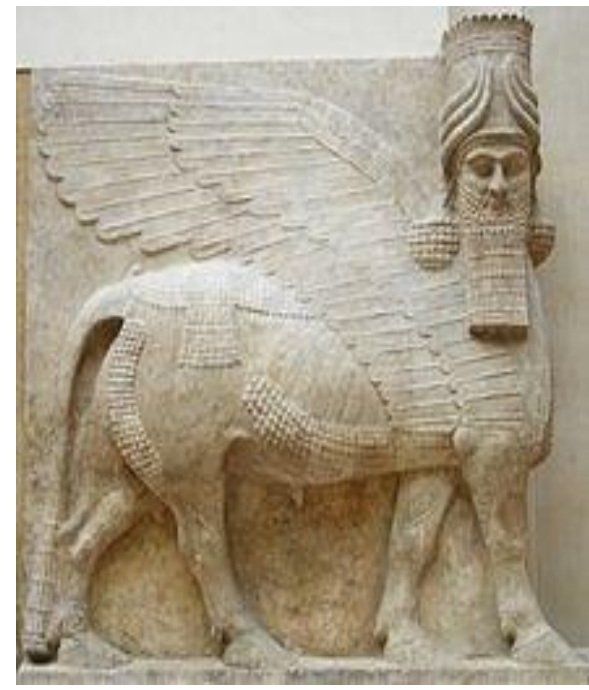

**شكل-16-16) أحد الثيران المجنحة الآثورية)

*: Janson, H.W.( 1980): History of Art, Abrams , N.Y. , p. 75

** http.ar. Wikipedia.org 


\section{بوابة شيتيا- كريها -كهوف أجانتا - الهند}

عالم أجانتا، كان قد وجد من خلال رغبة الرهبان البوذيون بالابتعـاد عن عالم الضجيج في المدن، وبحثهم عن و ادي صغير منعزل، يضمن تتدفقا لجداول المياه تحت الصخور ، وذلك لكي يعيشوا ويمارسوا طقوسهم الدينية في كهوفهم في قلب الصخر ، بعيدا عن صخب المدن . فكان الظهور الفريد لعمارة الكهوف التي أتخمت بالأعمال الفنية من المنحوتات الضخمة والصغيرة، والرسومات الملونة المنتشرة على الواجهات

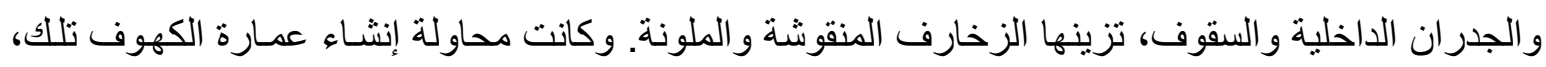
بسبب الظروف التي اشرنا لها ، قد قادت إلى ظهور هذه الصياغة الفنية الجديدة خـلال فترة امتدت لقرنين

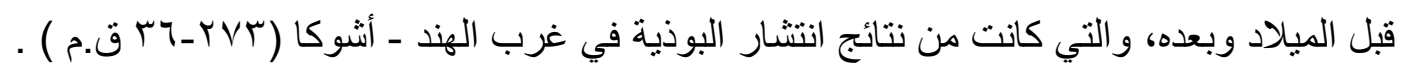

وبو ابة شيتيا كريها التي ترتفع حوالي أحد عشر مترا و عرضها يقترب من عشرة أمتار * ،هي بوابـة

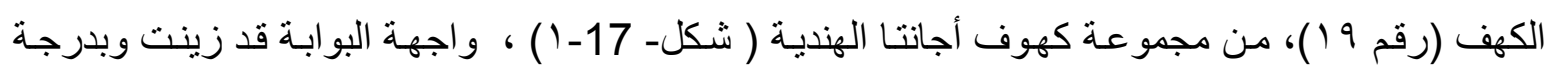
كبيرة، بمجموعة غنية من أعمال النحت الجداري تتخللها زخارف تتوزع على الأعمدة التي تحيط بـالفجوات الغائرة التي نحتت عليها التماثيل ـ وقد توزعت تلك التماثيل الجداريـة بكثافة على جانبي العمودين المؤديان إلى مدخل البوابة ـ كما تقف التماثيل على جانبي القوس الكبير الذي يتوسط الطابق الثاني للبوابـة. وقد حفرت تلك الأعمال الفنية التي تمثل أسطورة شيتيا على الصخور .ومن الكهف (رقم VI)، و على الأضـلاع الثلاثـة التي تحيط بواجهة المدخل الرئيسي لدير التعبد ، رسمت مجموعة من اللوحات الفنية توزعت على شكل ثمـان

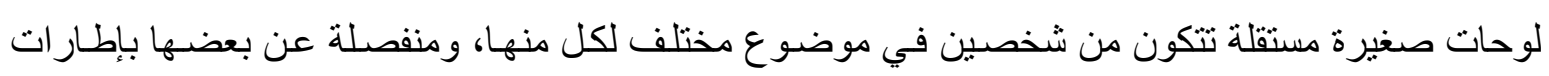
على شكل أعمدة معمارية تتخللها زخـارف، ورسم فوقها صف مكون من سبع شخصيات منفصلة لبوذنيين

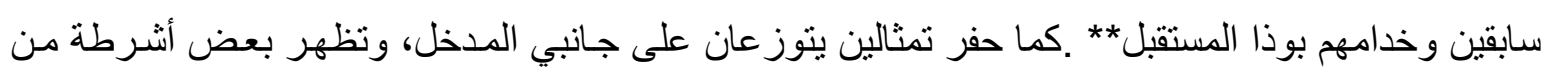
الزخرفة الملونة على الإطار القريب من المدخل.الألوان المستخدمة في الرسومات والزخـارف يغلب عليها الأحمر والأصفر الأوكر والأبيض و الأسود. و تبدو اللوحات بشكلها العام وكأنها صممت على شكل إطسار ات التهن

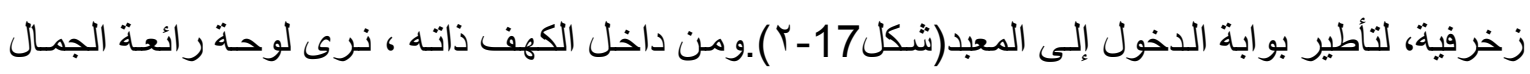
بألو انها وبأنتكال تكويناتها الزخرفية المتنو عة التي جاءت بمقاسات مربعة تتوسطها لوحات مستطيلة الثكل

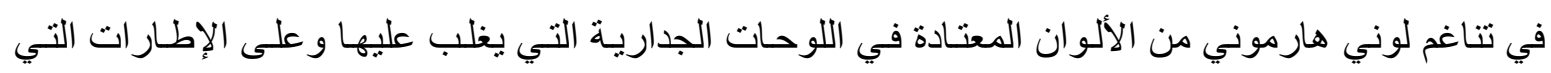
تفصل بينها ، اللون الأصفر الأوكر .( شكل- 17-بم).

* Ghosh, A.( , 1987) : Ajanta Murals , Archaeological Survey of India,

N.Delhi,pl. LXII

** Ghosh, A.( , 1987) : Ajanta Murals ,p. 32 


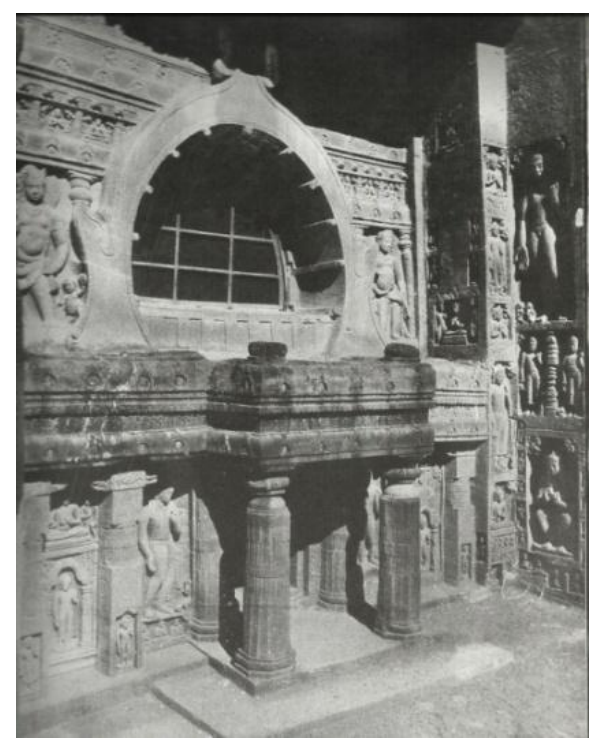

(شكل17- ا ) ) واجهة بوابة شيتيا_ كريهاأوالكهف 19 ، أجانتا ،الهند*

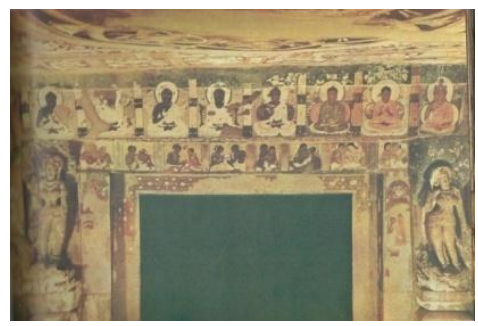

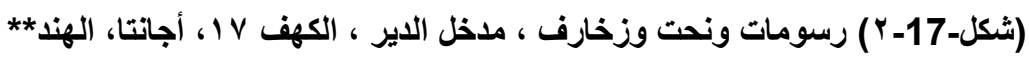

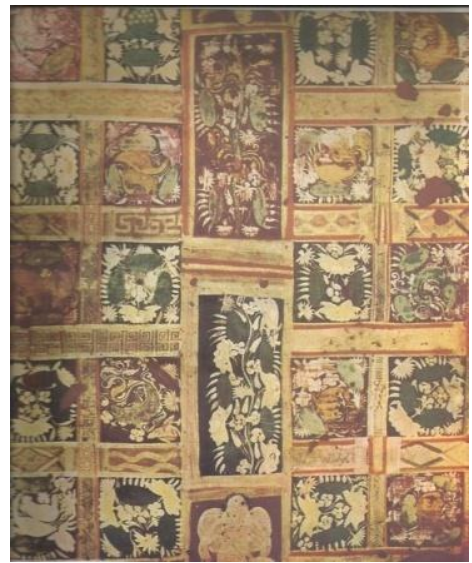

(شكل-17-17) لوحة زخرفية من سقف الكهف V V ا أجانتا ، الهند

${ }^{*},{ }^{* *},{ }^{* * *}$, Ghosh, A.( 1987) : Ajanta Murals, Archaeological Survey of India, N. Delhi, , pl. A , LXII, LXXXIII

\section{المبـثث الثالث - مقارنة ومقاربـة}

لتأكيد مدى تأثثر الفنون على المباني المعماريـة من خـلال وجود العلاقة الوثثقة بينها ،ليس في العصور القديمة التي حفلت بالأسباب الموجبة لها ، سحرية كانت أم دينية أو سياسية تاريخية، فإن ما سيتناوله 
هذا المبحث، يهدف إلى تحقيق أكبر قدر من الفائدة لتوضيح فكرة البحث، من خـلال تقديم بعض النمـاذج المختارة من مر احل لاحقة ترتبط بموضوع البحث . 1 - قبة الصخرة ــ القلس الشريف ــ فلسطين

تتميز قبة الصخرة بشكلها المثنم، وقبتها البر اقة التي تتوسط المبنى والتي يبلغ قطر هـا عشرين متر ا تقريبا ـ و تكسو قاعدة القبة من الخارج ، الزخارف النباتية المحددة بأنكال عمودية مستطيلة وكأنها قطع من السجاد المعلق الذي يغلف قاعدة القبة. كما ينقسم المبنى المثمن الثكل من الخارج إلى قسمين ـ تكسو القسم الأعلى كتابات وزخارف من الفسيفساء بألو انها التي تتدرج بين الأزرق و الأخضر المزرق بشكلها العام، مـع

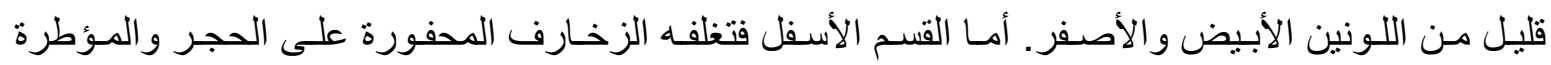

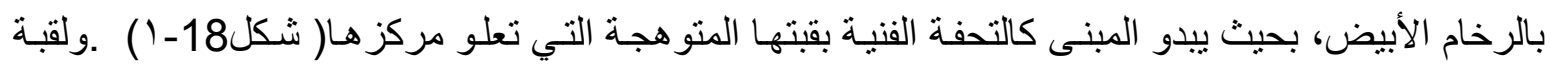

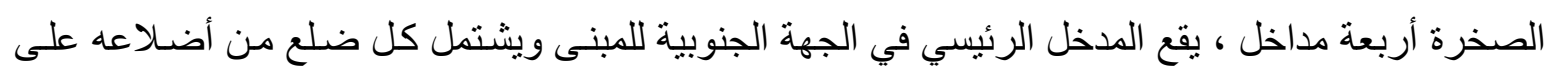

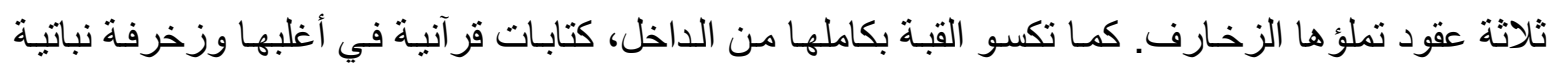
و هندسية تغطي مساحتها الداخلية مع سقف القبة.ويتذيل الكتابات الداخلية تاريخ ( اثثتان وسبعون) بإنـارة إلى تاريخ إنشائها.

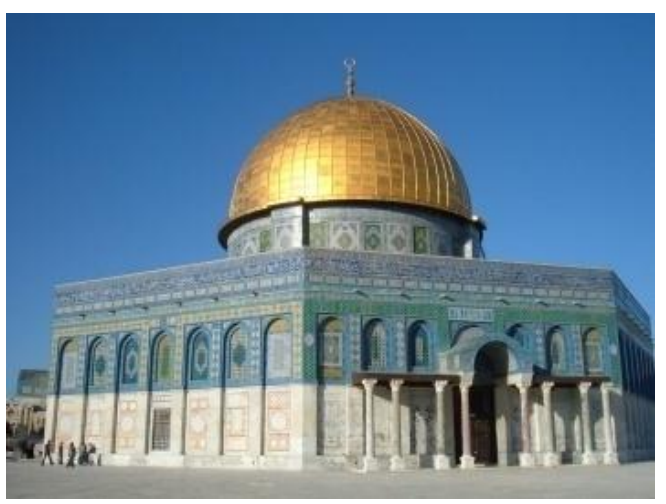

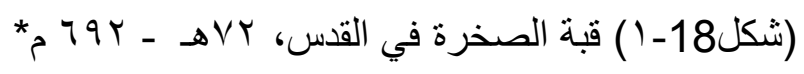

* http.ar. Wikipedia.org

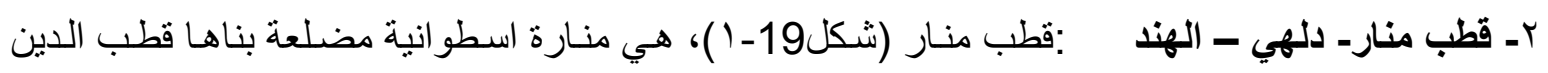

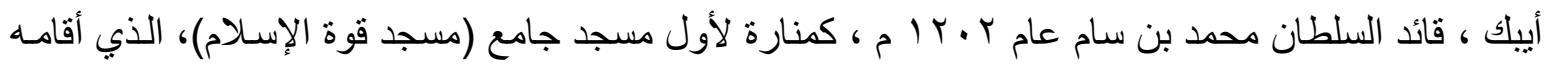
السلطان محمد بن سـام في مدينـة دلهي الهندية في سنة ONV هجريـة الموافق لسنة . 19 امث وكان بدون مئذنة. تتكون المئذنة من خمسة طوابق تحمل الطو ابق الثناثة الأولى المبنيـة من الحجر الأحمر، الكثير من الأشرطة البارزة المزينة بالخطوط العربية التي تحمل نصوص قرآنية وبعض المعلومـات التاريخية، تحدها زخارف نباتية روعة في جمالها وتقنيات تنفيذها. وتم بنـاء الطابقين الأخيرين بالرخام الأبيض الناصـع وقد زينت بالكتابات و الزخارف كذلك. 


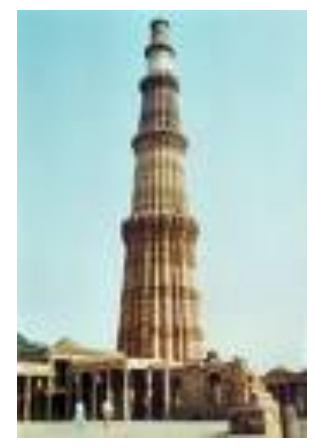

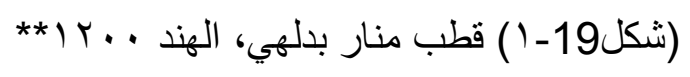

r- جامع الإمام موسى الكاظم - بغداد : يقف مبنى جامع الإمـام موسى الكاظم و الذي يضم قبره وقبر حفيده

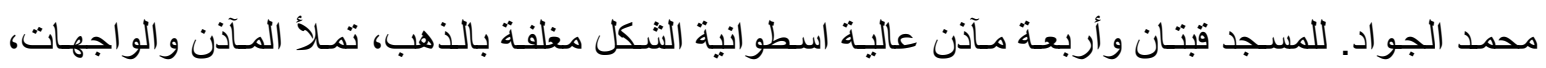
زخارف وكتابات روعة في جمالها و ألو انها التي تشكل لوحة فنية جميلة، ترتفع المـآنن فوق السقف همتركا

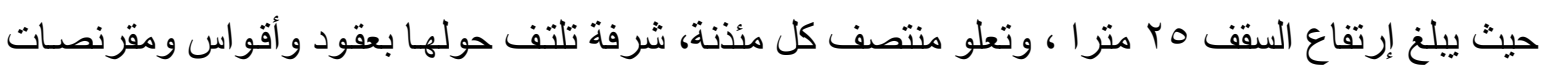
تقف على تـاج يعلو الجزءء الأول مـن المنـارة التي تجسـ الطراز العر اقي المميز في التصـيم المعــاري و الفني.(شكل- 20).

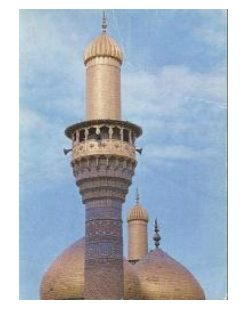

$$
\text { (شكل-20) مآذن وقباب جامع الإمام موسى الكاظم ببغداد ــ القرن } 10 \text { م }
$$

* Mohaisen, Jabbar H. (2002): The use of Arabic calligraphy in Indian Architecture \&

Painting ( PhD thesis), PU. India,p. 69

$$
\text { ** تصوير الباحث }
$$

*** http.ar. Wikipedia.org

عـ مسجد أصفهان - أصفهان - إيران : وفي إيران تتميز أغلب المسـاجد بمآذنها المزخرفة الملونـة والتي تتثابه كثير اً في تصميمها في أغلب المناطق التي كانت مر اكز مهمة، مثل أصفهان وتبريز وغيرها. وللمسجد الكبير في أصفهان الذي يعد من أشهر المساجد الإسلامية في إيران تمثيلاً للطراز الصفوي في إيران،المسجد

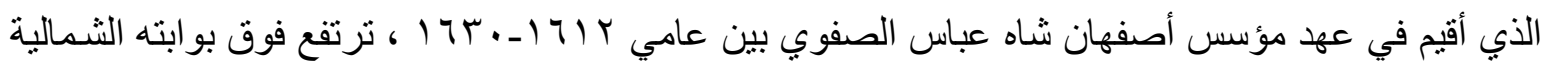

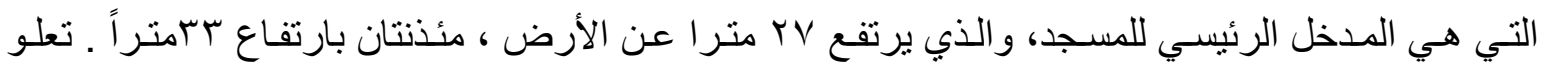
المآذن شرفات مقرنصة جميلة ، تكسو ها زخارف وكتابات بالسير اميك الملون الذي يطبعه اللون الفيروزي ، كباقي المآذن المشابهة المنتشرة في مناطق أخرى ( شكل -21). 


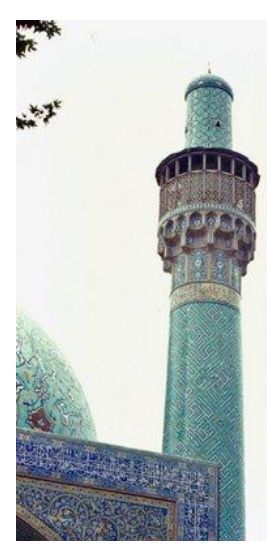

*IV (شكل-21) مأذنة مسجد اصفهان الكبير - ايران - القرن

هـ قبة كتدرائية توران - ايطاليا: تتميز القبة بالزخارف التي سجلت بشكلها الفني، رقمـا مهمـا في معادلة رؤية قبة الكنيسة التي يؤمها الناس للتعبد ( شكل -22)

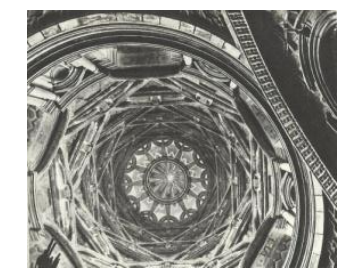

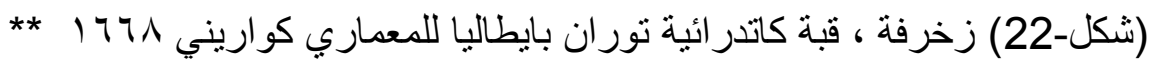

${ }^{*}$ http.ar. Wikipedia.org

**: Janson, H.W (1980): History of Art, Abrams , N.Y. , p. 501

T- واجهة كنيسة سانت فرانسيس - البرازيل: إضافة إلى شكل التصميم المعماري الذي يشبه الأيقونة الفنية ، فإن اللوحة الجدارية التي تغطي كامل واجهة المبنى ، تدلل على أهمية العلاقة بين الفن التشكيلي والمبنى كجسد فني واحد من الفنون المرئية تعزز القيمـة الجمالية الفن من مكانـة القيمـة الروحيـة للمبنى، بحيث ان تشخيص المبنى قد ارتبط ارتباطا وثيقا بالعمل الفني الذي أصبح مميز ا لهويته ( شكل-23)

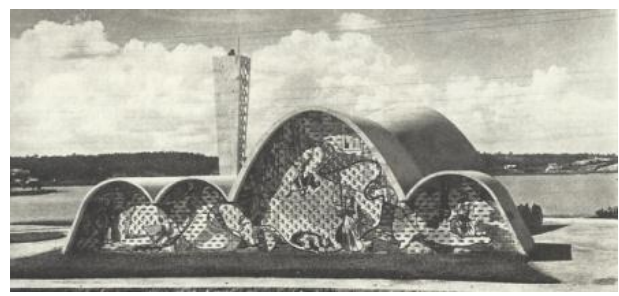

* شكل-23) كنيسة سانت فر انسيس بالبرازيل للمعماري اوسكار نايماير بـ 9 (ش

V- واجهة مبنى موندادوري- ميلان : مرة بعد أخرى ، يعزز الفن من مكانـة المبنى ليس في عصر من العصور ، و إنمـا في كل العصور ـ وعند النظر لواجهة المبنى لا نكاد أن نميز أو نفصل بين العمل الفني التشكيلي و المعدـاري. فـالعمود الذي صـمده الفنـان النحات ، جـاء بفكرة ورقتين بحالـة تفتح، وجـاء لليس 
منسجما بالمناصفة مـع شكل التصميم المعماري في حداثته فقط، و إنمـا تعدى ذلك إلى حد الهيمنـة بـالحجم و الموقع وجمالية الفكرة( شكل-24) .

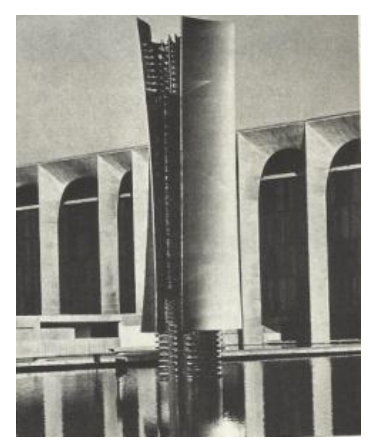

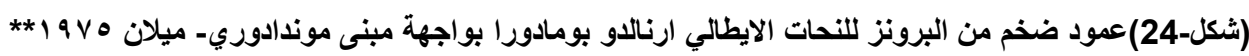

*,**, Arnason, H.H (1982): History of Modern Art, N.Y, , p. 473

نتائم البمث

بعد استعر اض العينات المستهدفة التي جمعت بشكل عفوي بين الأعمال الفنية التشكيلية و المباني

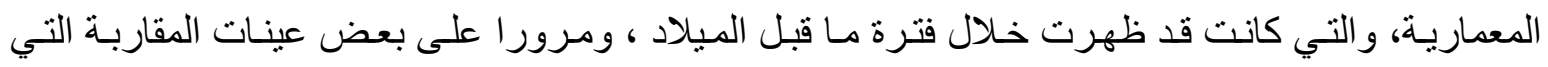
ظهـرت بـالفترات اللاحقـة ، نســطيع أن نسـتخلص بعض الاستتناجات التـي تتعلق بعناصـر التصـميم الفنـي و المعماري ومدى التأثثر الايجابي للفنون على المباني المعمارية وهي:

ا- إن الأفكار التي كانت وراء الأعمال الفنية المرتبطة بالمباني، كانت أصيلة ومبتكرة.

r- إن الأعمال المستهدفة الفنية والمعمارية لعصور ما قبل الميلاد ، كانت تمثل المدرسة الكلاسيكية.

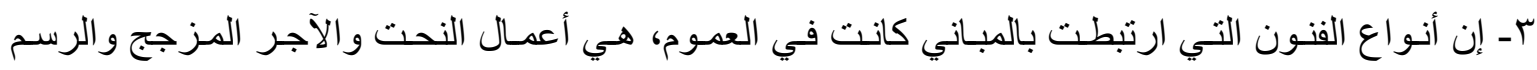
بالألوان، كما يظهر في تماثيل أبو سمبل في مصر ودور شيروكين في نينوى و عشتار في بابل وأجانتا في اللهند.

ع - تتميز أعمال النحت و البوابات بضخامتها لخلق التوازن بينهما من ناحية الكتلة و الفكرة. هـ إن معظم الأعمال الفنية التي إرتبطت بالمباني في عصور قبل المبلاد ، كانت قد مثلت مجتمعة أغر اضـا دينية وسياسية وجمالية مهارية، وكما تقف ور اءها فكرة تماثيل رمسيس الثناني في أبو سمبل و البوذا و الملك أثــوكا في أجانتـا والثـران المجنحـة و الملـك سـرجون الثـاني في دور شـيروكين وكذللك الثيـران والتــانين المزججة والملك نبو خذ نصر في بابل. 7- وجود مشتركات بطبيعة المواد الأولية بين الفنون و العمارة،كالجحر والرخام و الجبس والألوان و غير ها. V- و وجود مشتركات بين الفنون والمباني، في المصطلحات ومفردات العناصر التصميمية، كالخط و الثكل و الفر اغ و الكتلة و اللون و التخطيط و المنظور و غير ها. 
مـ تلازم موضوع العمل الفني مع المبنى منذ البدء بالمشروع، وبدون هذا التلازم ل لا نستطيع قر اءة فكرة العمل، و لا تتحقق الغاية التي وجد من خلالها المبنى. فلا يمكن تصور فكرة حراسة بوابة نبنوى بدون الثيران المجحة ، أو بو ابة أبو سمبل من دون التماثل الضخمة لرمسيس. 9- نلاحظ من خلال قر اءة الأعمـال اللاحقة المعروضـة، بـأن الفنون كانت ولاز زالت مهمة ودور هـا ريادي بعلاقتها بالمباني المعمارية مع بروز دور الخط العربي بشكل كبير إلى جانب الزخرفة ، في تزبين المساجد

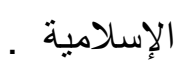

المسادر والمراجة العربية: ـ أبو دبسة ، فداء حسين ، خلود بدر غيث( (1 ـ ـ) : الفنون ما بين الحضارات القديمة والحديثة، دار الإعصار للثر ،عمان - جبرا ، إبراهيم جبر|(4 (91) ) : جذور الفن العراقي ، الدار العربية ، بغداد - حيدر، كاظم (ع (9/) : التخطيط والألوان ، جامعة بغداد ـ الربيعي، عبد الجبار حميدي(991 (191) : موجز تاريخ وتقنيات الفنون، دار البشير، عمان

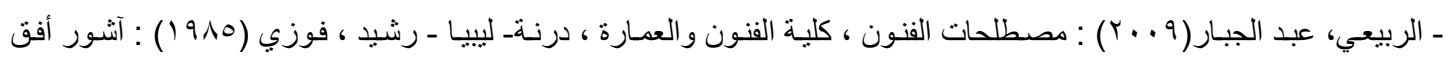

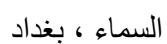
ـ الثنيخلي ، إسماعيل إبر اهيم (9V^ (1): المنظور ، جامعة بغداد - شيرز اد ، شيرين إحسان (ع 9 (1) ) : مبادئ في الفن والعمارة ، بغداد

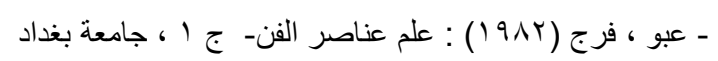

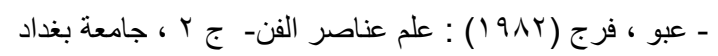
ـ مجموعة مؤلفين : محيط الفنون - الفنون التثكيلية ، دار المعارف بمصر . الأجنبية :

- Ghosh, A.( 1987) : Ajanta Murals, Archaeological Survey of India,N.Delhi,

.H.( 2002) : The use of Arabic Calligraphy in Indian Architecture and - Mohaisen, Jabbar Painting , (PhD. Thesis),PU.India - Arnason ,H.H. (1982): History of Modern Art,H.N.Abrams,N,Y. - Janson , H.W. (1977): History of Art , H.N.Abrams.N.Y. - Stan ,S. and H.F.T.Holt (1980): The Artist's Manual, Mayflower Books,N.Y.,

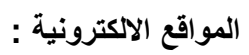
- http.ar.wikipedia.org 